Research Article

\title{
Determinants of Anemia in Pregnancy: Findings from the Ethiopian Health and Demographic Survey
}

\author{
Ataklti Gebretsadik Woldegebriel $\mathbb{D}^{1},{ }^{1}$ Gebremedhin Gebregziabiher Gebrehiwot $\mathbb{D}^{\mathbb{D}}{ }^{2}$ \\ Abraham Aregay Desta ${ }^{D}$, ${ }^{1}$ Kiros Fenta Ajemu $\left(\mathbb{D},{ }^{1}\right.$ Asfawosen Aregay Berhe, \\ Tewolde Wubayehu Woldearegay, ${ }^{1}$ and Nega Mamo Bezabih ${ }^{1}$
}

\author{
${ }^{1}$ Tigray Health Research Institute, Mekelle, Tigray, Ethiopia
}

${ }^{2}$ Adigrate University, Mekelle, Tigray, Ethiopia

Correspondence should be addressed to Ataklti Gebretsadik Woldegebriel; atakltigebertsadik@gmail.com

Received 25 February 2020; Revised 11 May 2020; Accepted 19 May 2020; Published 5 June 2020

Academic Editor: Duran Canatan

Copyright (c) 2020 Ataklti Gebretsadik Woldegebriel et al. This is an open access article distributed under the Creative Commons Attribution License, which permits unrestricted use, distribution, and reproduction in any medium, provided the original work is properly cited.

\begin{abstract}
In Ethiopia, anemia during pregnancy is a major public health problem and affects both the mother's and their child's health. There is a scarcity of community-based evidence on determinants of anemia among pregnant women in the country. Therefore, this study aimed to assess the determinants of anemia among pregnant women in Ethiopia. Method. This study was based on the 2016 Ethiopian Demographic Health Survey (EDHS) that used a two-stage stratified cluster sampling technique. A cross-sectional study was conducted among 3080 pregnant women. Data analysis was done using STATA v.14. Variables with $P$ value $<0.05$ in the bivariate analysis were candidates for the multivariable analysis to identify independent determinants of anemia among pregnant mothers. Odds ratios (OR) were calculated at 95\% confidence interval (CI). Results. The overall prevalence of anemia among pregnant women was $41 \%$ of which $20 \%$ were moderately anemic, $18 \%$, mildly anemic, and $3 \%$, severely anemic. The following were significantly associated with anemia during pregnancy: an age of 30-39 years, receiving no education $(\mathrm{AOR}=2.19 ; 95 \% \mathrm{CI}$ $1.45,2.49)$, belonging to the poorest wealth quintile ( $\mathrm{AOR}=1.29 ; 95 \% \mathrm{CI} 1.22,1.60)$, being a Muslim ( $\mathrm{AOR}=1.59 ; 95 \% \mathrm{CI} 1.69$, 2.65), number of house members being 4-6 ( $\mathrm{AOR}=1.44 ; 95 \% \mathrm{CI} 1.05,1.97)$, number of under-five children being two $(\mathrm{AOR}=1.47 ; 95 \% \mathrm{CI} 1.10,1.97)$, head of the household being a female $(\mathrm{AOR}=2.02 ; 95 \% \mathrm{CI} 1.61,2.54)$, current pregnancy wanted later $(\mathrm{AOR}=1.75 ; 95 \% \mathrm{CI} 1.23,1.63)$, no terminated pregnancy $(\mathrm{AOR}=1.49 ; 95 \% \mathrm{CI} 1.15,1.93)$, and an age of $13-17$ years at the first sexual intercourse $(\mathrm{AOR}=1.97 ; 95 \% \mathrm{CI} 1.291,3.00)$. Conclusions. The study revealed that more than one-third of the pregnant women in Ethiopia were found anemic. Its prevalence varied among regions in which the highest (62.7\%) and the lowest (11.9\%) were from Somali and Addis Ababa, respectively. Hence, efforts should be made by concerned bodies to intervene in terms of the identified risk factors.
\end{abstract}

\section{Introduction}

Anemia during pregnancy was defined by the World Health Organization and Center for Disease Control and Prevention (CDC) as a hemoglobin concentration of less than $11 \mathrm{~g} / \mathrm{dL}[1]$. Globally, prenatal anemia is observed as an indicator of adverse health and socioeconomic consequences. It impairs physical health, cognitive development, and productivity and reflects the poor economic development of a country $[2,3]$.
Globally, an estimated 32.4 million (38.2\%) pregnant women were anemic. Its burden was high in South East Asia (48.7\%) and in Africa (46.3\%) [2]. Sub-Saharan Africa took the greatest share, where 17.2 million pregnant women were reported anemic [4].

The causes of anemia during pregnancy in developing countries including Ethiopia were nutritional deficiencies of iron, vitamin B12, folate, and parasitic diseases, such as hookworm and malaria. The virtual input of each of these factors to anemia varies greatly in the community [5]. 
National nutrition program and micronutrient deficiency prevention and control strategy has been implemented in the country to reduce anemia among pregnant mothers [6,7]. Despite the various efforts made by the government and other stakeholders, maternal anemia is still a major public health concern $[8,9]$.

Study findings showed variety of results: Southern Ethiopia (27\%) [5]; Arba Minch, Ethiopia (32.8\%) [10]; Eastern Tigray, Northern Ethiopia (7.8\%) [11]; Gondar, Northern Ethiopia (16.6 \%) [12]; North West Ethiopia (30\%) [13]; North Shoa Zone, Ethiopia (10\%) [14].

Even though pocket studies were conducted in various settings of the country and most shreds of evidence lack consistency and unrepresentative samples, there is scarce community-based evidence showing national representatives. Therefore, this community-based and national-wide study was conducted to assess the determinant factors of anemia among pregnant women. The result of this study will be used for national-level policy making and programming by concerned bodies to intervene and lessen the high burden of the disease.

\section{Materials and Methods}

The data used in this analysis were downloaded from the Demographic and Health Survey (DHS) Program website. Administratively, regions in Ethiopia are divided into zones, and zones, into administrative units, called woreda. The 2016 EDHS was conducted on a nationally representative sample of nine regions and two city administrations of the country. They were subdivided into 68 zones, 817 districts, and 16,253 kebeles (lowest local administrative units of the nation).

The EDHS is a periodical survey with a five-year interval; sometimes, in special cases, the interval is different. The 2016 EDHS is the fourth and the most recent DHS in Ethiopia, following 2000, 2005, and 2011 EDHS surveys.

2.1. Study Design. A community-based cross-sectional study design was conducted at the national level as one part of the periodic EDHS. The survey was conducted with nationally representative samples from all of the regions of the country. The details of the sample design and sampling procedure, including the sampling framework and implementation and response rates, are provided in the respective EDHS reports (http://www.measuredhs.com/).

2.2. Sampling Procedure. The 2016 EDHS data are by now chosen using a stratified, two-stage cluster design, and the enumeration areas were the sampling units for the first stage. In the first stage, 645 enumeration areas were randomly selected: 202 in urban areas and 443 in rural areas. In the second stage, a fixed number of 28 households per cluster were selected randomly for each enumeration area. 18,008 households were randomly selected, and 16,650 households were eligible and interviewed. Additional information about the methodology of EDHS 2016 can be accessed in the report of the main findings of the survey published [13].
2.3. Data Extraction Methods. EDHS 2016 data were downloaded, with permission, from the measure DHS website in SPSS. After a review of the detailed data coding, further data recoding was completed. In the 2016 EDHS dataset, there were 3327 pregnant mothers, of whom 155 pregnant mothers were excluded from the analysis data due to missed hemoglobin data. Information on a wide range of sociodemographic, economic, household, and obstetric characteristics, anemia level, and other indicators were extracted.

2.4. Measurement and Operational Definition. Anemia status was determined based on hemoglobin concentration in blood adjusted to the altitude. Anemia was defined as the occurrence of a hemoglobin level of less than $11 \mathrm{~g} / \mathrm{dL}$. It was further categorized into mild, moderate, and severe anemia with a hemoglobin range of $10-<11 \mathrm{~g} / \mathrm{dl}, 7-<10 \mathrm{~g} / \mathrm{dl}$, and $<7 \mathrm{~g} / \mathrm{dl}$, respectively.

2.5. The Study Population. The study population was randomly selected pregnant mothers who have hemoglobin data in their data record in the archive of EDHS 2016 data.

\subsection{Variables in the Study}

2.6.1. The Outcome Variable. The outcome variable is the anemia status of pregnant mothers.

2.6.2. Covariates Variables. To investigate the determinants of anemia among pregnant mothers, a number of sociodemographic, health, and socioeconomic factors, such as maternal and paternal characteristics, household characteristics, and environmental conditions, were assessed.

2.7. Data Analysis. After the data were extracted, they were checked for its completeness and consistency, and we did the preliminary analysis. Data analysis was carried out using STATA version v.14. Sample weights were applied to compensate for the unequal probability of selection between the strata, which has also been geographically defined for nonresponses. A detailed explanation of the weighting procedure can be found in the EDHS methodology report [13]. We used "svy" in STATA v.14 to weight the survey data and perform the analyses.

Descriptive statistics was done to describe the data such as frequencies and percentages. Anemia status was determined based on hemoglobin concentration in blood adjusted to altitude. Adjusted concentration less than $11 \mathrm{~g} / \mathrm{dl}$ was considered as anemic.

Logistic regression method was used to identify the determinants of anemia. Bivariate analysis was performed to determine the crude association of each covariate variables with the outcome variable (anemia status). Those covariate variables with $P$ value less than 0.20 in the bivariate analysis were included in the final multivariable logistic regression analysis to adjust for the confounding variable and to identify the final determinant of anemia among pregnant mothers. We use the backward logistic regression method 
during the multivariable logistic regression analysis. Before inclusion of predictors to the final logistic regression model, the multicollinearity was checked using $\mathrm{VIF}<10 /$ tolerance $>0.1$ for continuous independent variables. The goodness of fit of the final logistic model was tested using Hosmer-Lemeshow test at $P$ value of $>0.05$. Outcome measures have been indicated by odds ratio with $95 \%$ confidence interval. Finally, covariate variables with $P$ value of $<0.05$ in the multivariable logistic regression model were considered as statistically significant variables in the final logistic model.

2.8. Ethical Considerations. The study proposal has received an ethical approval from Tigray Health Research Institute, and a formal letter of permission was obtained from measure DHS project website to access the dataset (http://www.measuredhs. com).

\section{Results}

3.1. Sociodemographic and Household Characteristics of Pregnant Mothers. Data on 3080 pregnant mothers were included in the final analysis. The mean age was 15 years with a $\mathrm{SD}$ of \pm 1.5 . Half of the pregnant mothers were in the age group of $30-39$ years. $88.5 \%$ of them are rural residents, $76.5 \%$ are currently not working, and $75 \%$ are illiterate. Around half of the pregnant mothers (43.3\%) belong to the poorest wealth index (Table 1). 55.7\% have an improved source of drinking water, and $54.6 \%$ have an improved type of toilet facility. $84 \%$ did not have electricity, and $75.3 \%$ have no radio. Around half of the households have 4-6 children (Table 2).

3.2. Obstetric Characteristics of Pregnant Mothers. Around half of the pregnant women (46.6\%) did not follow the ANC, two thirds (62.3\%) did not receive iron during pregnancy, and $62.5 \%$ received iron for 1-30 days. More than three fourth $(88.5 \%)$ have never had a terminated pregnancy, 93.4\% have not received a drug for intestinal parasite, and $92 \%$ had a postnatal checkup (Table 3 ).

\subsection{Anemia Prevalence and Level and Regional Distribution} among Pregnant Mothers. The prevalence of anemia among pregnant women was $41 \%$. Twenty percent had moderate anemia, 18\%, mild anemia, and 3\%, severe anemia (Figure 1). There was a wide regional variation of anemia level among pregnant mothers in Ethiopia. The highest anemia level (62.7\%) was found in Somali regional state and the lowest in Addis Ababa (11.9 \%) (Figure 2).

3.4. Factors Associated with Anemia among Pregnant Mothers. As shown in Table 4, the binary logistic regression of mother's age, residence, maternal educational status, religion, number of household members, number of underfive children, sex of household head, having a bank account, wealth index, if the current pregnancy is wanted, having a terminated pregnancy, age at first sexual intercourse, husband's desire for more children, and if the mother is currently working were significantly associated.
TABLE 1: Sociodemographic and other characteristics of pregnant mothers, EDHS $2016(n=3082)$.

\begin{tabular}{lcc}
\hline Variables & Frequency & Percentage (\%) \\
\hline Maternal age (years) & & \\
$<20$ years & 31 & 1 \\
$20-29$ & 1202 & 39 \\
$30-39$ & 1584 & 51.4 \\
$40-49$ & 265 & 8.6 \\
\hline Residence & & \\
Rural & 2723 & 88.4 \\
Urban & 359 & 11.6 \\
\hline Mother's educational level & \\
Illiterate & 2313 & 75 \\
Primary & 616 & 20 \\
Secondary & 106 & 3.4 \\
Higher & 47 & 1.6 \\
\hline Currently working & & \\
Yes & 723 & 23.5 \\
No & 2359 & 76.5 \\
\hline Wealth index combined & & \\
Poorest & 1347 & 43.7 \\
Poorer & 534 & 17.3 \\
Middle & 423 & 13.7 \\
Richer & 423 & 13.7 \\
Richest & 355 & 11.5 \\
\hline
\end{tabular}

TABLE 2: Household characteristics of pregnant mothers, EDHS $2016(n=3082)$.

\begin{tabular}{lcc}
\hline Variables & Frequency & Percentage \\
\hline Sources of drinking water & & \\
Improved & 1714 & 55.7 \\
Nonimproved & 1336 & 43.3 \\
Others & 32 & 1 \\
\hline Type of toilet facility & & \\
Improved & 1682 & 54.6 \\
Nonimproved & 1400 & 45.4 \\
\hline Having electricity & & \\
Yes & 464 & 15. \\
No & 2588 & 84 \\
Not a de jure residence & 30 & 1 \\
\hline Having a radio & & \\
Yes & 730 & 23.7 \\
No & 2322 & 75.3 \\
Not a de jure residence & 30 & 1 \\
\hline Having a television & & 6.6 \\
Yes & 203 & 92.4 \\
No & 2849 & 1 \\
Not a de jure residence & 30 & 9.9 \\
\hline Number of household members & & 48.3 \\
$1-3$ & 287 & 2.5 \\
$4-6$ & 1405 & \\
$7-9$ & 1142 & 72 \\
$\geq 10$ & & \\
\hline
\end{tabular}

The maternal age of 30-39 years was significantly associated with anemia (adjusted odds ratio $(\mathrm{AOR})=1.72$ $(1.24,2.39))$ compared with an age of less than 20 years. Receiving no education was significantly associated with 
TABLE 3: Obstetric characteristics of pregnant mothers, EDHS $2016(n=3082)$.

\begin{tabular}{lcc}
\hline Variables & Frequency & Percentage \\
\hline ANC visit & 344 & 46.6 \\
No ANC visit & 213 & 28.7 \\
$1-3$ & 185 & 24.9 \\
$\geq 4$ & & \\
\hline Receiving iron during pregnancy & 277 & 37.3 \\
Yes & 462 & 62.3 \\
No & & \\
\hline Days of iron given & 170 & 62.5 \\
$1-30$ & 45 & 16.5 \\
$31-60$ & 57 & 21 \\
$>60$ & 355 & 11.5 \\
\hline Ever having a terminated pregnancy & 2727 & 88.5 \\
Yes & & 6.1 \\
No & 45 & 93.4 \\
\hline Drug for intestinal parasite & 693 & 8 \\
Yes & & 92 \\
No & 59 & 683 \\
\hline Postnatal checkup & & \\
Yes & & \\
No & & \\
\hline
\end{tabular}

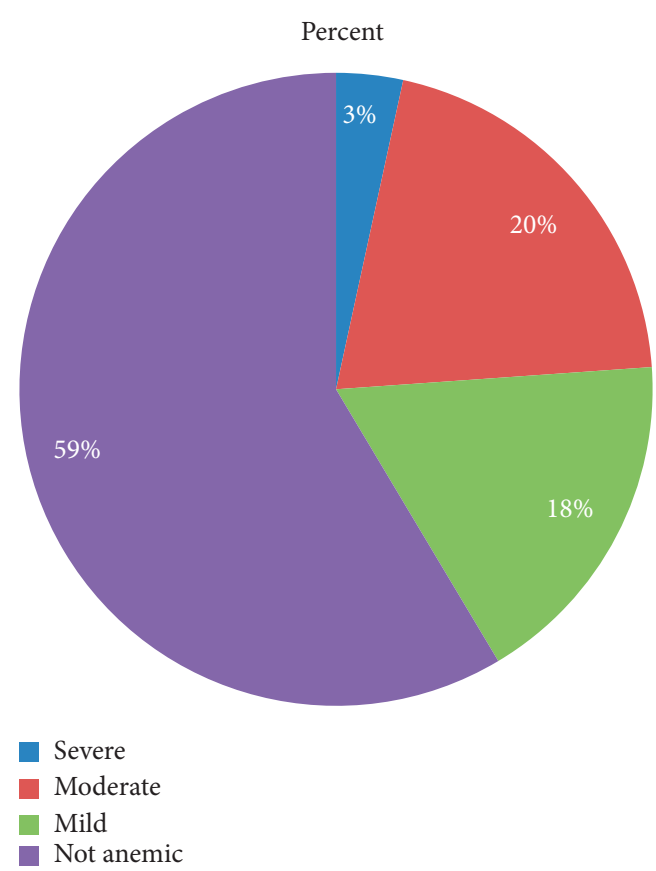

Figure 1: Anemia level among pregnant mothers, EDHS 2016 $(n=3082)$.

anemia (adjusted odds ratio $(A O R)=2.19(1.45,2.49)$ ). Being a Muslim was significantly associated with anemia (adjusted odds ratio $(\mathrm{AOR})=2.12(1.69,2.65))$ compared with being Orthodox. The presence of 4-6 members in a household was significantly associated with anemia (adjusted odds ratio $(\mathrm{AOR})=1.44(1.05,1.97))$ compared with a household having 1-3 members

The presence of 1-3 under-five children in a household was significantly associated with anemia (adjusted odds ratio
$(\mathrm{AOR})=1.47(1.10,1.97))$ compared with having no underfive children. A household head being a female was significantly associated with anemia (adjusted odds ratio $($ AOR $)=2.02(1.61,2.54))$ compared with a male household head. Belonging to the poorest wealth index was significantly associated with anemia (adjusted odds ratio $(\mathrm{AOR})=1.29$ $(1.22,1.62))$ compared with the richest wealth index. Wanting the current pregnancy (adjusted odds ratio $(A O R)=1.93(1.44,2.60))$ and wishing the current pregnancy happened later (adjusted odds ratio $(\mathrm{AOR})=1.75$ $(1.23,2.49)$ ) were significantly associated with anemia.

Not having a terminated pregnancy was significantly associated with anemia (adjusted odds ratio $(A O R)=1.49$ $(1.15,1.93))$ compared with having a terminated pregnancy. An age of 13-17 years (adjusted odds ratio $(A O R)=1.97$ $(1.29,3.00))$ and $\geq 18$ years (adjusted odds ratio $(A O R)=1.59$ $(1.02,2.49))$ at the first sexual intercourse were significantly associated with anemia compared with an age of 13 years at the first sexual intercourse $(\mathrm{AOR}=1.29 ; 95 \%$ CI $(1.014$, 1.60)).

\section{Discussion}

Anemia increases the risk of maternal and child morbidity and mortality. It also impairs cognitive and physical development of children and decreases work efficiency in adults [15]. This study showed that the prevalence of anemia among pregnant women was $41 \%$ of which $20 \%$ were moderately anemic; $18 \%$, mildly anemic; $3 \%$, severely anemic. Identified factors were older age (30-39 years), being illiterate, belonging to the poorest wealth quintile, number of household members being 4-6, number of underfive children being two, household head being a female, current pregnancy wanted later, no terminated pregnancy, 


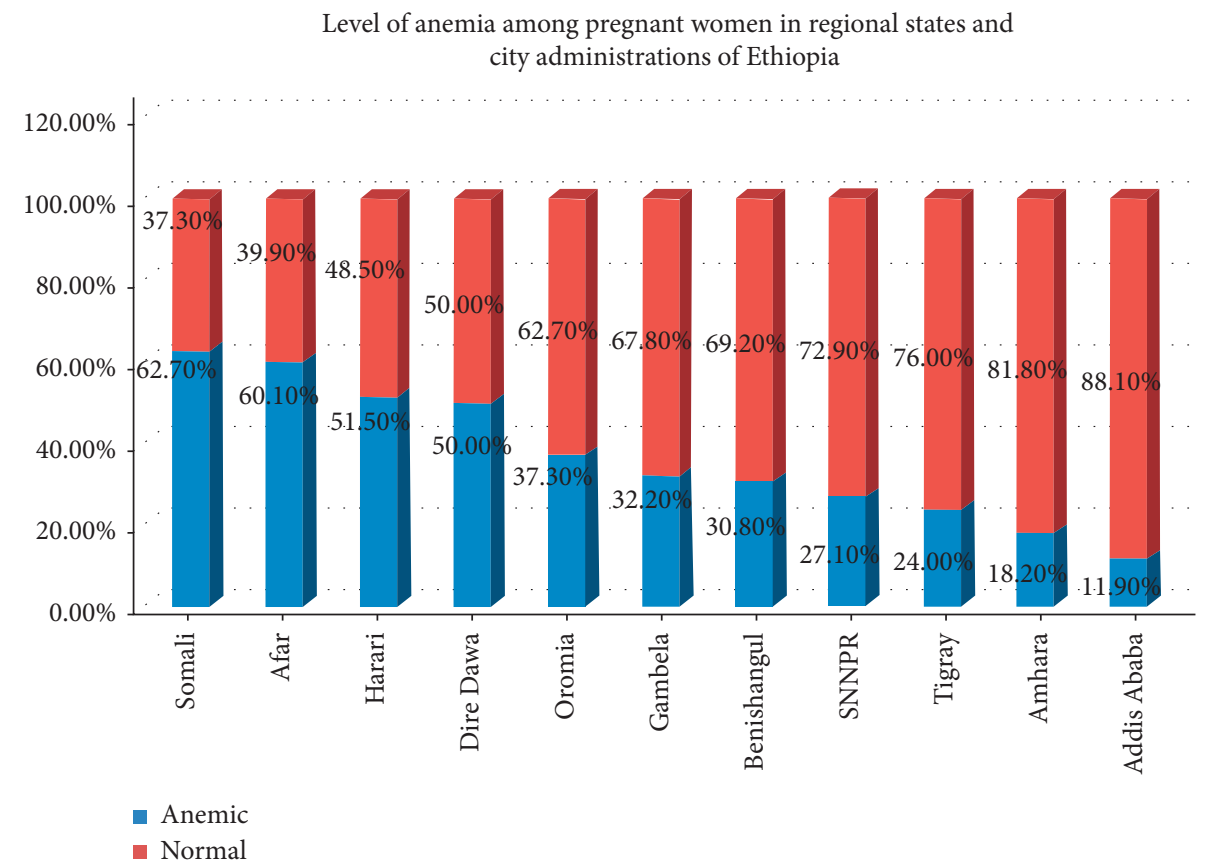

FIGURE 2: Regional distribution of anemia among pregnant mothers $(n=3082)$.

TABle 4: Parameter estimates of related covariates in the final proportional odds model of pregnant mothers, EDHS 2016 ( $n=3082)$.

\begin{tabular}{|c|c|c|c|c|c|c|c|}
\hline \multirow{2}{*}{ Variables } & & \multicolumn{2}{|c|}{ Anemia } & \multirow{2}{*}{ COR $(95 \% \mathrm{CI})$} & \multirow{2}{*}{$P$ value } & \multirow{2}{*}{$\operatorname{AOR}(95 \% \mathrm{CI})$} & \multirow{2}{*}{$P$ value } \\
\hline & & Yes, $n(\%)$ & No, $n(\%)$ & & & & \\
\hline \multirow{4}{*}{ Maternal age } & $<20$ years & $12(38.7)$ & $19(61.3)$ & $\begin{array}{c}2.068(0.951 \\
4.496)\end{array}$ & 0.067 & $\begin{array}{c}0.847(0.343 \\
2.094)\end{array}$ & 0.719 \\
\hline & $20-29$ & $495(41.2)$ & $707(58.8)$ & $\begin{array}{c}2.292(1.687 \\
3.115)\end{array}$ & $<0.001^{*}$ & $\begin{array}{c}1.133(0.790 \\
1.623)\end{array}$ & 0.498 \\
\hline & $30-39$ & $708(44.7)$ & $876(55.3)$ & $\begin{array}{c}2.646(1.958 \\
3.576)\end{array}$ & $<0.001^{*}$ & $\begin{array}{c}1.725(1.241 \\
2.397)\end{array}$ & $0.001^{*}$ \\
\hline & $40-49$ & $62(23.4)$ & $203(76.6)$ & 1 & & 1 & \\
\hline \multirow[b]{2}{*}{ Residence } & Urban & $144(40.1)$ & $215(59.9)$ & 1 & & & \\
\hline & Rural & $1133(41.6)$ & $\begin{array}{c}1590 \\
(58.4) \\
\end{array}$ & $\begin{array}{c}1.064(0.850 \\
1.332)\end{array}$ & 0.588 & & \\
\hline \multirow{4}{*}{ Maternal educational status } & No education & $\begin{array}{c}1022 \\
(44.2 \%)\end{array}$ & $\begin{array}{c}1291 \\
(55.8)\end{array}$ & $2.309(1.1924 .471)$ & $0.013^{*}$ & $2.19(1.45,2.49)$ & $0.01^{*}$ \\
\hline & Primary & $201(32.6)$ & $415(67.4)$ & $\begin{array}{c}1.413(0.718 \\
2.780)\end{array}$ & 0.317 & $\begin{array}{c}0.845(0.393 \\
1.817)\end{array}$ & 0.666 \\
\hline & Secondary & $42(39.6)$ & $64(60.4)$ & $\begin{array}{c}1.914(0.893 \\
4.103)\end{array}$ & $0.095^{*}$ & $\begin{array}{c}1.314(0.576 \\
2.999)\end{array}$ & 0.516 \\
\hline & Higher & $12(25.5)$ & $35(74.5)$ & 1 & & 1 & \\
\hline \multirow{4}{*}{ Religion } & Orthodox & $175(25.7)$ & $505(74.3)$ & 1 & & 1 & \\
\hline & Protestant & $141(29.4)$ & $338(70.6)$ & $\begin{array}{c}1.204(0.927 \\
1.563)\end{array}$ & 0.164 & $\begin{array}{c}0.997(0.751 \\
1.323)\end{array}$ & 0.982 \\
\hline & Muslim & $940(51.2)$ & $896(48.8)$ & $\begin{array}{c}3.027(2.492 \\
3.678)\end{array}$ & $<0.001^{*}$ & $\begin{array}{c}2.117(1.693 \\
2.649)\end{array}$ & $<0.001^{*}$ \\
\hline & Others & $21(24.1)$ & $66(75.9)$ & $\begin{array}{c}0.918(0.546 \\
1.545)\end{array}$ & 0.748 & $\begin{array}{c}0.722(0.421 \\
1.238)\end{array}$ & 0.237 \\
\hline \multirow{4}{*}{ Number of $\mathrm{HH}$ members } & $1-3$ & $105(36.6)$ & $182(63.4)$ & 1 & & 1 & \\
\hline & $4-6$ & $641(45.6)$ & $764(54.4)$ & $\begin{array}{c}1.454(1.119 \\
1.890)\end{array}$ & $0.005^{*}$ & $\begin{array}{c}1.443(1.055 \\
1.973)\end{array}$ & $0.022^{*}$ \\
\hline & $7-9$ & $446(39.1)$ & $696(60.9)$ & $\begin{array}{c}1.111(0.850 \\
1.452)\end{array}$ & 0.442 & $\begin{array}{c}0.937(0.659 \\
1.332)\end{array}$ & 0.716 \\
\hline & $\geq 10$ & $85(34.3)$ & $163(65.7)$ & $\begin{array}{c}0.904(0.633 \\
1.290)\end{array}$ & 0.578 & $\begin{array}{c}0.716(0.457 \\
1.122)\end{array}$ & 0.145 \\
\hline
\end{tabular}


TABle 4: Continued.

\begin{tabular}{|c|c|c|c|c|c|c|c|}
\hline \multirow{2}{*}{ Variables } & & \multicolumn{2}{|c|}{ Anemia } & \multirow{2}{*}{ COR $(95 \%$ CI $)$} & \multirow{2}{*}{$P$ value } & \multirow{2}{*}{ AOR $(95 \% \mathrm{CI})$} & \multirow{2}{*}{$P$ value } \\
\hline & & Yes, $n(\%)$ & No, $n(\%)$ & & & & \\
\hline \multirow{4}{*}{ Number of under-five children } & 0 & $128(35.0)$ & $238(65.0)$ & 1 & & 1 & \\
\hline & 1 & $385(34.9)$ & $717(65.1)$ & $\begin{array}{c}0.998 \\
(0.779,1.279)\end{array}$ & 0.990 & $\begin{array}{c}0.953(0.721 \\
1.260)\end{array}$ & 0.738 \\
\hline & 2 & $611(48.5)$ & $648(51.5)$ & $\begin{array}{c}1.753 \\
(1.377,2.232)\end{array}$ & $<0.001^{*}$ & $\begin{array}{c}1.471(1.100 \\
1.966)\end{array}$ & $0.009^{*}$ \\
\hline & $\geq 3$ & $153(43.1)$ & $202(56.9)$ & $\begin{array}{c}1.408 \\
(1.043,1.902) \\
\end{array}$ & $0.026^{*}$ & $\begin{array}{c}0.988(0.690 \\
1.415)\end{array}$ & 0.949 \\
\hline \multirow{2}{*}{ Sex of HH head } & Male & $988(38.1)$ & $\begin{array}{c}1604 \\
(61.9)\end{array}$ & 1 & & 1 & \\
\hline & Female & $298(59.0)$ & $201(41.0)$ & $\begin{array}{c}2.334 \\
(1.917,2.842)\end{array}$ & $<0.001^{*}$ & $\begin{array}{c}2.025(1.614 \\
2.540)\end{array}$ & $<0.001^{*}$ \\
\hline \multirow[b]{2}{*}{ Having a bank account } & Yes & $40(19.6)$ & $164(80.4)$ & 1 & & 1 & \\
\hline & No & $1237(43.0)$ & $\begin{array}{c}1641 \\
(57.0)\end{array}$ & $\begin{array}{c}3.091 \\
(2.170,4.401)\end{array}$ & $<0.001^{*}$ & $\begin{array}{c}2.049(1.376 \\
3.051)\end{array}$ & $>0.001^{*}$ \\
\hline \multirow{5}{*}{ Wealth index } & Poorest & $684(50.8)$ & $663(49.2)$ & $\begin{array}{c}2.153 \\
(1.682,2.755)\end{array}$ & $<0.001^{*}$ & $1.29(1.223,1.643)$ & $>0.001^{*}$ \\
\hline & Poorer & $206(38.6)$ & $328(61.4)$ & $\begin{array}{c}1.311 \\
(0.988,1.738)\end{array}$ & $0.060^{*}$ & $\begin{array}{c}0.926(0.671 \\
1.279)\end{array}$ & 0.641 \\
\hline & Middle & $123(29.1)$ & $300(70.9)$ & $\begin{array}{c}0.856 \\
(0.630,1.162)\end{array}$ & 0.318 & $\begin{array}{l}0.666(0.475 \\
1.735)\end{array}$ & $0.719^{*}$ \\
\hline & Richer & $149(35.2)$ & $274(64.8)$ & $\begin{array}{c}1.135 \\
6(0.842,1.530)\end{array}$ & 0.406 & $\begin{array}{c}0.970(0.697 \\
1.351)\end{array}$ & 0.859 \\
\hline & Richest & $115(32.4)$ & $240(67.6)$ & 1 & & 1 & \\
\hline \multirow{3}{*}{ Current pregnancy wanted } & Then & $1027(44.2)$ & $\begin{array}{c}1295 \\
(55.8)\end{array}$ & $\begin{array}{c}2.370 \\
(1.829,3.070)\end{array}$ & $<0.001^{*}$ & $\begin{array}{c}1.934 \\
(1.439,2.600)\end{array}$ & $<0.001^{*}$ \\
\hline & Later & $165(39.2)$ & $256(60.8)$ & $\begin{array}{c}1.926 \\
(1.407,2.637)\end{array}$ & $<0.001^{*}$ & $\begin{array}{c}1.756 \\
(1.236,2.495)\end{array}$ & $0.002^{*}$ \\
\hline & Not at all & $85(25.1)$ & $254(74.9)$ & 1 & & 1 & \\
\hline \multirow[b]{2}{*}{ Ever had terminated pregnancy } & Yes & $113(31.8)$ & $242(68.2)$ & 1 & & 1 & \\
\hline & No & $1164(42.7)$ & $\begin{array}{c}1563 \\
(57.3)\end{array}$ & $\begin{array}{c}1.595 \\
(1.260,2.019)\end{array}$ & $<0.001^{*}$ & $\begin{array}{c}1.489 \\
(1.147,1.935)\end{array}$ & $0.003^{*}$ \\
\hline \multirow{3}{*}{ Age at first sexual intercourse } & $<13$ years & $35(23.3)$ & $115(76.7)$ & 1 & & 1 & \\
\hline & 13-17 years & $880(42.8)$ & $\begin{array}{c}1175 \\
(57.2)\end{array}$ & $\begin{array}{c}2.461 \\
(1.669,3.628)\end{array}$ & $<0.001^{*}$ & $\begin{array}{c}1.966 \\
(1.286,3.004)\end{array}$ & $0.002^{* *}$ \\
\hline & $\geq 18$ years & $362(41.3)$ & $515(58.7)$ & $\begin{array}{c}2.310 \\
(1.546,3.451) \\
\end{array}$ & $<0.001^{*}$ & $\begin{array}{c}1.596 \\
(1.023,2.489) \\
\end{array}$ & $0.039^{*}$ \\
\hline \multirow{4}{*}{$\begin{array}{l}\text { Husband's desire for more } \\
\text { children }\end{array}$} & Both want the same & $396(40.8)$ & $574(59.2)$ & 1 & & 1 & \\
\hline & $\begin{array}{c}\text { Husband wants } \\
\text { more }\end{array}$ & $536(49.4)$ & $550(50.6)$ & $\begin{array}{c}1.413(1.186 \\
1.682)\end{array}$ & $<0.001^{*}$ & $\begin{array}{c}1.093 \\
(0.901,1.326)\end{array}$ & 0.368 \\
\hline & $\begin{array}{l}\text { Husband wants } \\
\text { fewer }\end{array}$ & $67(34.5)$ & $127(65.5)$ & $\begin{array}{c}0.765 \\
(0.554,1.056)\end{array}$ & $0.103^{*}$ & $\begin{array}{c}0.924 \\
(0.652,1.309)\end{array}$ & 0.656 \\
\hline & Do not know & $272(34.1)$ & $526(65.1)$ & $\begin{array}{c}0.750 \\
(0.617,0.910) \\
\end{array}$ & $0.004^{*}$ & $\begin{array}{c}0.629 \\
(0.507,0.780) \\
\end{array}$ & $<0.001^{*}$ \\
\hline \multirow[b]{2}{*}{ Respondent currently working } & Yes & $302(41.8)$ & $421(58.2)$ & 1 & & & \\
\hline & No & $975(41.3)$ & $\begin{array}{c}1384 \\
(58.7)\end{array}$ & $\begin{array}{c}0.982 \\
(0.829,1.163) \\
\end{array}$ & 0.834 & & \\
\hline
\end{tabular}

being a Muslim, and an age of 13-17 years at first sexual intercourse.

The magnitude of anemia in this study was $41 \%$. The results of this study are consistent with the studies done in Mangalore (41.5\%) [16] and Northern Gana (42.7\%) [17], while they show a lower prevalence compared with a study conducted in the field practice area of a medical college (81.8\%) [18] and a nationally representative survey in India (62.6\%).
On the other hand, the results of this study show a higher prevalence compared with study in North West Ethiopia (30.5\%) [13]. This could be explained by an extra demand for iron by pregnant women for fetal growth and development during pregnancy and an inability to fulfill the required demand. These differences in the prevalence of anemia might be due to variations in socioeconomic status, attention given for focused antenatal care and supplementation of iron 
sulfate throughout the pregnancy, dietary patterns, sample size, and geographical and lifestyle variations.

In the present study, noneducated pregnant women were significantly associated with anemia. This finding is consistent with previous reports $[18,20,21]$. The possible reason for this might be the fact that educated pregnant women have a better income and knowledge that in turn help them to follow better lifestyle behaviors like consuming iron-rich nutritious foods and better healthseeking habits like the intake of sufficient iron tablets during antenatal care.

Another finding of this study is that being pregnant with an age of 30-39 years was significantly associated with anemia. This is consistent with previous reports $[18,19]$. This might be because as maternal age increases, the mother may face repetitive and relentless pregnancies, endure the collective result of the exhausting labor-related complications, and be subjected to other illnesses which may predispose her for anemia.

The head of the household being a female was significantly associated with anemia during pregnancy. According to EDHS 2016 report in Ethiopia, the majority of households' heads were males [22]. Females have limited control over the materialistic and social resources in Ethiopia. Food and nutrients are allocated inequitably within the households with an obvious male benefit.

Male household heads consume more animal-source foods, eat special foods and drink alcohol outside of their home, and have an uppermost dietary adequacy, whereas women eat more low-status foods and have lower dietary adequacy, particularly pregnant women due to their high requirements.

In addition to this, most of the time males are also responsible for paying for health care expenses. The number of household members being 4-6 is significantly associated with anemia during pregnancy. This is in line with the study conducted in India, Gamo Gofa Zone, and Oromia region, Ethiopia $[10,23,24]$. Since pregnant mothers consume a larger amount of food, food insecurity is one of the underlying causes of anemia, and food-insecure households were at increased risk of pregnancy anemia.

An increased number of children in the household are significantly associated with prenatal anemia. This is also in line with a study in Eastern and Northern Ethiopia and Mangalore as the result showed that unplanned pregnancies, number of pregnancies, and increased number of children have a negative effect on prenatal anemia $[16,25,26]$. This might be due to the association of anemia in pregnancy with food insecurity with the increased number of under-five children.

Pregnant women with the poorest economic status were at the highest risk of anemia, when compared with their wealthy counterpart. This finding was similar to reports in developing countries like Ethiopia, Uganda, and South Asia. [27-29]. This might be due to the fact that having a low income would mean having less money to buy iron-containing nutritious foods or have a balanced diet. As a result, it leads to an insufficient diet and anemic and poor health outcomes.
This study showed that pregnant women who had a terminated pregnancy before were likely to have anemia compared to women who did not have one. In contrast with reports in Adigrate and Bahir Dar, Ethiopia, and teaching Hospital of Mangalor [16, 30, 31], we could not find any report supporting this finding and therefore further study is needed.

4.1. Strength and Limitation of the Study. This study used large population-based data with a large sample size, which is representative of all regions of Ethiopia. These findings will present useful information for policy makers to decrease the prevalence of anemia during pregnancy in all regions of the country.

This study made use of cross-sectional data from 2016 Ethiopian Demographic and Health Survey, which does not allow the identification of the precedence in time between exposure and outcome (chicken egg dilemma). Furthermore, EDHS was a questionnaire-based survey and relied on the memory of the respondents, and as such, recall bias in the results might be a weakness for this study.

\section{Conclusion}

More than one-third of the pregnant women in Ethiopia were anemic. Regions with high anemia prevalence among pregnant women should be given due consideration. The factors associated with anemia in this study population were maternal age, belonging to the poorest wealth index, being a Muslim, number of household members being four to six, number of under-five children being two, the head of the household being a female, the current pregnancy wanted later, no terminated pregnancy, and an age of 13-17 years at the first sexual intercourse. The observed prevalence of anemia might affect the birth outcome of pregnant women. The concerned bodies should focus on enhancing and emphasizing the interventions targeting the identified factors to reduce the high prevalence of anemia among pregnant women in the country.

\section{Data Availability}

The database and study materials are available upon request directly to the authors.

\section{Ethical Approval}

Ethical clearance was obtained from the Institutional Review Board of Tigray Health Research Institute and the analyses of this study are confined to secondary data. Approval to analyze the secondary data is requested from the CSA or ORC Macro (Demographic and Health Survey). The authors have been authorized to download data from the Demographic and Health Surveys (DHS) online.

\section{Conflicts of Interest}

The authors declare that they have no conflicts of interest. 


\section{Authors' Contributions}

AW contributed to the concept and data collection tool, conducted data extraction, analysis, and interpretation, and wrote the first draft of the manuscript and revised it. GG, $\mathrm{AD}, \mathrm{AB}, \mathrm{KA}, \mathrm{TW}$, and $\mathrm{NB}$ contributed to data curation, protocol development, and data analysis and revised the manuscript draft. All authors read and approved the final manuscript.

\section{Acknowledgments}

The authors sincerely show their deepest gratitude to Tigray Health Research Institute for giving advice. The authors are also very grateful to Measure DHS for making the data freely available.

\section{References}

[1] World Health organization, Essential Nutrition Action-Improving Maternal, New Born Infant and Young Children Health and Nutrition, WHO, Geneva, Switzerland, 2014.

[2] WHO, The Global Prevalence of Anemia in 2011, World Health Organization, Geneva, Switzerland, 2015.

[3] G. A. Stevens, M. M. Finucane, L. M. De-Regil et al., "Global, regional, and national trends in hemoglobin concentration and prevalence of total and severe anemia in children and pregnant and non-pregnant women for 1995-2011: a systematic analysis of population-representative data," Lancet Global Health, vol. 1, no. 1, pp. 16-25, 2013.

[4] T. Susan and D. O. Blackburn, "Maternal, fetal, \& neonatal physiology, clinical perspective," Qualitative Health Research, vol. 11, no. 6, pp. 780-794, 2007.

[5] W. Getahun, T. Belachew, and A. D. Wolide, "Burden and associated factors of anemia among pregnant women attending antenatal care in southern Ethiopia: cross sectional study," BMC Research Notes, vol. 10, p. 276, 2017.

[6] Federal Ministry of Health and Family Health Department Ethiopia, National Guideline For Control and Prevention of Micronutrient Deficiencies, Federal Ministry of Health, Family Health Department Ethiopia, Addis Ababa, Ethopia, 2004.

[7] Government of the federal democratic and republic of Ethiopia, National Nutrition Program, 2015.

[8] CSA, "Ethiopia demographic and health survey," Preliminary Report, CSA, Addis Ababa, Ethiopia, 2011.

[9] F. W. Lone, R. N. Qureshi, and F. Emanuel, "Maternal anaemia and its impact on perinatal outcome," Tropical Medicine \& International Health, vol. 11, no. 6, pp. 780-794, 2004.

[10] B. Alemayehu, T. Marelign, and M. Aleme, "Prevalence of anemia and its associated factors among pregnant women attending antenatal care in health institutions of arba minch town, gamogofa zone, Ethiopia: a cross-sectional study," Anemia, 2016.

[11] B. Brhane, M. Fitsum, L. Haftom, G. Aderajew, G. Guesh, and KebedeT, "Prevalence of anemia and associated factors among pregnant women in adigrat general hospital,tigrai, northern Ethiopia," BMC Research Notes, vol. 12, p. 310, 2019.

[12] M. Melku, Z. Addis, M. Alem, and B. Enawgaw, "Prevalence and predictors of maternal anemia during pregnancy in gondar, northwest Ethiopia: an institutional based crosssectional study," Anemia, vol. 2014, Article ID 108593, 9 pages, 2014.
[13] T. Derso, "Magnitude and associated factors of anemia among pregnant women in Dera District: a cross-sectional study in northwest Ethiopia," BMC Research Notes, vol. 10, p. 359, 2017.

[14] F. A. Mekonnen, Y. A. Ambaw, and G. T. Neri, "Socioeconomic determinants of anemia in pregnancy in North Shoa zone, Ethiopia," PLoS one, vol. 13, no. 8, 2018.

[15] WHO, Focusing on Anaemia: Towards an Integrated Approach for Effective Anaemia Control, World Health Organization, Geneva, Switzerland, 2004.

[16] P. R. N. PreetiTiwari, A. S. Nirgude, and S. Shetty, "Prevalence of anemia and associated factors in pregnant women in a teaching hospital of Mangalore," International Journal of Health Sciences \& Research, vol. 5, p. 7, 2015.

[17] E. A. Nonterah, E. Adomolga, A. Yidana et al., "Descriptive epidemiology of anaemia among pregnant women initiating antenatal care in rural Northern Ghana," African Journal of Primary Health Care \& Family Medicine, vol. 11, no. 1, 2019.

[18] V. Kumar, M. Jain, U. Shukla, M. Swarnkar, P. Gupta, and P. Saini, "Prevalence of anemia and its determinants among pregnant women in a rural community of jhalawar, Rajasthan," National Journal of Community Medicine, vol. 10, no. 4, pp. 207-211, 2019.

[19] V. Lin, "Prevalence, risk factors and associated adverse pregnancy outcomes of anaemiainChinese pregnant women: a multicentre retrospective study," BMC Pregnancy and Childbirth, vol. 18, p. 111, 2018.

[20] A. Gebre and A. Mulugeta, "Prevalence of anemia and associated factors among pregnant women in north western zone of tigray, northern Ethiopia: a cross-sectional study," Journal of Nutrition and Metabolism, vol. 2015, Article ID 165430, 7 pages, 2015.

[21] A. Hailu, "Determinant factors of anemia amongpregnant women attending antenatal care clinic in northwest ethiopia," Tropical Diseases, Travel Medicine and Vaccines, vol. 5, p. 13, 2019.

[22] Ethiopian Central Statistical Agency, Ethiopia Demographic And Health Survey, Ethiopian Central Statistical Agency, Addis Ababa, Ethopia, 2016.

[23] J. Yadav, "Prevalence and factor Associated with maternal anaemia in India: analysis of A nationally representative crosssectional survey, 2012-13," BAOJ Hematology, vol. 1, 2017.

[24] N. Obse, A. Mossie, and T. Gobena, "Magnitude of anemia and associated risk factors among pregnant women attending antenatal care in shalla woreda, west arsi zone, oromia rRegion, Ethiopia," Ethiopian Journal of Health Sciences, vol. 23, no. 2, pp. 165-73, 2013.

[25] K. Addis Alene and A. Mohamed Dohe, "Kefyalew addis alene1 and abdulahi mohamed dohe.prevalence of anemia and associated factors among pregnant women in an urban area of eastern ethiopia," Anemia, vol. 2014, 2014.

[26] T. Grum, E. Brhane, S. Hintsa, and G. Kahsay, "Magnitude and factors associated with anemia among pregnant women attending antenatal care in public health centers in central zone of yigray region, northern Ethiopia: a cross sectional study," BMC Pregnancy and Childbirth, vol. 18, p. 433, 2018.

[27] K. T. Kibret, C. Chojenta, E. D'Arcy et al., "Spatial distribution and determinant factors of anaemia among women of reproductive age in Ethiopia: a multilevel and spatial analysis," BMJ Open, vol. 9, Article ID e027276, 2019.

[28] O. Nankinga and D. Aguta, "Determinants of Anemia among women in Uganda: further analysis of the Uganda demographic and health surveys," BMC Public Health, vol. 19, pp. 1757-1828, 2019.

[29] H. Fry, "Determinants of intra-household food allocation between adults in South Asia-a Systematic review," International Journal for Equity in Health, vol. 16, p. 107, 2017. 
[30] A. Berheet, "Prevalence of anemia and associated factors among pregnant women in adigrat general hospital, tigrai, northern Ethiopia, 2018," BMC Research Notes, vol. 12, p. 310, 2019.

[31] D. Getaneh, A. Bayeh, B. Belay, T. Tsehaye, and Z. Mekonnen, "Assessment of the prevalence of anemia and its associated factors among pregnant women in Bahir dar city administration, north-west Ethiopia," Journal of Pregnancy and Child Health, vol. 5, p. 367, 2018. 